\title{
DESEMPENHO E QUALIDADE DE OVOS DE POEDEIRAS DE 50 A 66 SEMANAS DE IDADE SUPLEMENTADAS COM PROBIÓTICO
}

\author{
PERFORMANCE AND EGG QUALITY FROM 50 TO 66-WEEKS-OLD-LAYING- \\ HENS SUPPLEMENTED PROBIOTIC
}

\author{
Adriana Ayres Pedroso $^{1}$ Vera Maria Barbosa Moraes ${ }^{2}$ Joji Ariki $^{2}$
}

RESUMO

Objetivou-se, com este trabalho, avaliar o efeito de probiótico sobre o desempenho e qualidade de ovos de poedeiras. A suplementação de probiótico foi iniciada na fase de recria e os efeitos foram avaliados de 50 a 66 semanas. $O$ delineamento experimental adotado foi inteiramente ao acaso com quatro tratamentos (suplementação de probiótico na fase de recria e postura, suplementação de probiótico somente na fase de recria, suplementação de probiótico somente na fase de postura e ausência de suplementação) e seis repetições de oito aves cada. Nas fases de recria e postura, as rações continham 15,50 e 17,00\% de proteína bruta e 2800 e $2750 \mathrm{kcal}$ de energia metabolizável/kg. Os resultados de consumo de ração $(106,53,110,81,107,25$, $109,72 \mathrm{~g})$, produção de ovos $(85,20,83,66,79,18,81,94 \%)$, peso de ovos $(59,84,60,53,61,11,60,33 \mathrm{~g})$, conversão alimentar por $d z$ $(1,50,1,59,1,64,1,61)$ e por $k g(2,09,2,19,2,24,2,22)$, espessura de casca $(0,387,0,384,0,386,0,381 \mathrm{~mm})$, porcentagem de casca (9,44, 9,43, 9,37, 9,31\%), unidade Haugh $(92,50,93,14,91,34$, 91,57) e gravidade específica $(1,0856,1,0851,1,0850,1,0839)$ não indicaram qualquer diferenças entre os tratamentos $(P>0,05)$. A utilização do Bacillus subtilis como agente probiótico, quando utilizado a partir da recria, da postura ou durante as duas fases, não possibilita melhoras no desempenho e qualidade de ovos de poedeiras de 50 a 66 semanas de idade.

Palavras-chave: Bacillus subtilis, desempenho, poedeiras, probiótico, qualidade de ovos.

\section{SUMMARY}

The experiment was carried out to evaluate probiotic on laying hen performance and egg quality. The probiotic was fed from pullet phase and the effects were evaluate from 50 to 66 weeks. A completely randomized experimental design with four treatments (probiotic suplementation in pullet and laying phase, probiotic suplementation only in pullet phase, probiotic suplementation only in laying phase and no

\begin{abstract}
suplementation), and six replicates of eight birds each was used. The rations contained 15.50 and $17.00 \%$ crude protein and 2800 and $2750 \mathrm{kcal}$ metabolizable energy/kg respectively in pullet and laying phases. The results of feed intake (106.53, 110.81, 107.25, $109,72 \mathrm{~g})$, egg production $(85.20,83.66,79.18,81.94 \%)$, egg weight $(59.84,60.53,61.11,60.33 \mathrm{~g})$, alimentary conversion per $d z(1.50,1.59,1.64,1.61)$, and per $\mathrm{kg}(2.09,2.19,2.24,2.22)$, shell thickness $(0.387,0.384,0.386,0.381 \mathrm{~mm})$, shell percent (9.44, 9.43, 9.37, 9.31\%), Haugh unit (92.50, 93.14, 91.34, 91.57) and specific gravity $(1.0856,1.0851,1.0850,1.0839)$ did not indicate any treatment effect $(P>0.05)$. The utilization of Bacillus subtilis as probiotic during pullet phase, laying phase or pullet and laying phases did not improve the performance and egg quality of laying hens from 50 to 66 weeks of age.
\end{abstract}

Key words: Bacillus subtilis, performance, probiótico, laying hen, egg quality.

\section{INTRODUÇÃO}

A cada ano, mais antibióticos utilizados como promotores de crescimento animal são proibidos por entidades que regulamentam a saúde pública. Nos últimos anos, produtos como bacitracina de zinco, espiramicina, fosfato de tilosina e virginamicina foram vetados para a administração animal na Europa. Essa atitude reflete a preocupação de alguns órgãos com a possibilidade de serem encontrados resíduos de drogas em carne e ovos destinados ao consumo humano. A opinião pública também tem exercido pressão para que sejam produzidos alimentos livres de drogas promotoras de crescimento ditos "mais saudáveis", e um mercado com conside-

\footnotetext{
${ }^{1}$ Zootecnista, Doutorando em Ciência Animal e Pastagens, Departamento de Produção Animal, ESALQ, Universidade de São Paulo, Av. Pádua Dias 11, 13418-900, Piracicaba, SP. E-mail: adrianap@ carpa.ciagri.usp.br. Autor para correspondência.

${ }^{2}$ Docente, Departamento de Zootecnia, Faculdade de Ciências Agrárias e Veterinárias, Universidade do Estado de São Paulo, Jaboticabal, São Paulo.
} 
rável poder aquisitivo, disposto a pagar mais por produtos diferenciados, cresce dia-a-dia. $\mathrm{Na}$ esperança de atender a esses anseios, pesquisadores têm estudado o efeito promotor de crescimento que alguns microrganismos podem apresentar e, paralelamente, a iniciativa privada impulsiona a área, colocando à disposição do produtor novos produtos no mercado.

Alguns microrganismos, denominados probióticos, quando administrados através da água ou da ração, podem estabelecer uma relação de simbiose no trato intestinal trazendo benefícios (FÜLLER \& COLE, 1988). A esses agentes, é atribuída a capacidade de melhorar a conversão alimentar (HADDADIN et al., 1996) e a produção de ovos (TORTUERO \& FERNÁNDEZ, 1995), aumentar a espessura da casca (GHAZALAH $\boldsymbol{e} \boldsymbol{t}$ al. 1988; MOHAN et al., 1995; HADDADIN et al., 1996) e o peso dos ovos (MILES et al., 1981, GOODLING et al., 1987, NAHASHON et al., 1992) e melhorar qualidade interna de ovos (NAHASHON et al., 1994a).

O período de fornecimento do probiótico parece influenciar os resultados obtidos em experimentos. ABDULRAHIM et al. (1996) demonstraram que a qualidade do ovo pode ser influenciada pela época de administração. Avaliando a qualidade da casca de ovos poedeiras até 45 semanas de idade suplementadas com probiótico a base de Bacillus subtilis, PEDROSO et al. (1999) observaram que a utilização precoce do agente (a partir da fase de recria) foi mais efetiva que a utilização tardia (a partir da fase de postura) ao melhorar a espessura da casca.

Alguns resultados contraditórios também são relatados. DAMRON et al. (1981), analisando o efeito de Lactobacillus e PHEKOS et al. (1998), avaliando o efeito de uma preparação comercial na alimentação de poedeiras, não observaram resultados favoráveis ao uso dos agentes sobre o desempenho das aves e qualidade interna e da casca dos ovos. HENRIQUE (1998), ZUANON et al. (1998) e LODDI (1999) também não observaram efeitos satisfatórios sobre o desempenho de frangos de corte quando utilizaram dietas com diversas preparações comerciais de probiótico. GIAMPAULI et al. (1999) analisando o desempenho e a qualidade de ovos de poedeiras submetidas a preparações comerciais de $\boldsymbol{B}$. subtilis, após a muda forçada, não observaram qualquer benefício na adição do microrganismo na dieta.

Com base nesses dados, o trabalho foi elaborado, objetivando estabelecer o efeito e a melhor época de administração de probiótico a base de B. subtilis através dos resultados de desempenho e de qualidade de ovos avaliados a partir da $50^{\mathrm{a}}$ semana de idade de poedeiras.

\section{MATERIAL E MÉTODOS}

O experimento foi realizado no aviário experimental da Faculdade de Ciências Agrárias e Veterinárias da Universidade Estadual Paulista de Jaboticabal, com duração de 16 semanas, divididos em quatro ciclos de quatro semanas cada. Foram utilizadas galinhas Lohmann com 50 semanas, dividas em 24 parcelas, sendo cada unidade experimental composta de oito aves. O delineamento utilizado foi inteiramente casualizado com quatro tratamentos e seis repetições. As rações (Tabela 1) foram formuladas de acordo com o NATIONAL RESEARCH COUNCIL (NRC, 1994). O microrganismo utilizado foi o $\boldsymbol{B}$. subtilis, na concentração de $3 \times 10^{10}$ células viáveis por grama de produto (Calsporin $10^{\circledR}$, comercializado pela Fatec SA). Os tratamentos experimentais representaram os diferentes períodos de suplementação, da $8^{\mathrm{a}}$ até a $17^{\mathrm{a}}$ semana, da $8^{\mathrm{a}}$ até a $66^{\mathrm{a}}$ semana, da $18^{\mathrm{a}}$ a $66^{\mathrm{a}}$ semana e um grupo controle sem suplementação. Com a única finalidade de atender as exigências nutricionais das aves, as dietas oferecidas na fase de postura foram classificadas em postura I e II. As variáveis de desempenho e qualidade de ovos foram analisadas pelo procedimento General Linear Models do SAS ${ }^{\circledR}$ (SAS INSTITUTE, 1998).

Tabela 1- Composição percentual e níveis nutricionais das dietas experimentais.

\begin{tabular}{lrrr}
\hline \multicolumn{1}{c}{ Ingredientes (\%) } & Recria & Postura I & Postura II \\
& & & \\
\hline & & & \\
Milho moído & 63,81 & 62,68 & 62,00 \\
Óleo de soja & - & 0,28 & 0,47 \\
Farelo de soja & 16,95 & 25,58 & 25,68 \\
Farelo de trigo & 15,28 & - & - \\
Cálcario & 1,85 & 8,47 & 9,38 \\
Fosfato bicálcico & 0,99 & 2,04 & 1,87 \\
Sal & 0,30 & 0,30 & 0,30 \\
DL-Metionina, 99\% & - & 0,04 & - \\
Suplemento mineral e vitaminico & 0,15 & 0,10 & 0,10 \\
Antioxidante - Banox & - & 0,05 & 0,05 \\
Areia lavada ${ }^{2}$ & 0,67 & 0,46 & 0,15 \\
Total & 100,00 & 100,00 & 100,00 \\
& & & \\
Níveis calculados: & & & \\
& & & \\
Energia metabolizável, kcal/kg & 2800 & 2750 & 2750 \\
Proteína Bruta, \% & 15,50 & 17,00 & 17,00 \\
Lisina, \% & 0,72 & 0,88 & 0,88 \\
Metionina + Cistina, \% & 0,53 & 0,60 & 0,56 \\
Cálcio, \% & 1,00 & 3,70 & 4,00 \\
Fósforo disponível, \% & 0,30 & 0,45 & 0,42 \\
& & & \\
& &
\end{tabular}

${ }^{1}$ Composição por kg vit. A- 8.000 .000 UI, vit. D3- 2.100.000U.I., vit. E$7.000 \mathrm{mg}$, vit. K3- $2.000 \mathrm{mg}$, vit. B1- $1000 \mathrm{mg}$, vit. B2- $3000 \mathrm{mg}$, vit. B6$700 \mathrm{mg}$, vit. B $12-6.000 \mathrm{mcg}$, Niacina- $20.000 \mathrm{mg}$, Biotina- $10 \mathrm{mg}$, Pantotenato de Cálcio- $10.000 \mathrm{mg}$, Ácido Fólico- $100 \mathrm{mg}$, Se- $200 \mathrm{mg}$, Mn $55.000 \mathrm{mg}, \mathrm{Zn}-50.000 \mathrm{mg}, \mathrm{Cu}-6000 \mathrm{mg}, \mathrm{Fe}-50.000 \mathrm{mg}$, I- $1000 \mathrm{mg}, \mathrm{Co}-$ $100 \mathrm{mg}$, Antioxidante- $2000 \mathrm{mg}$, Veículo q.s.p.- $1000 \mathrm{~g}$.

${ }^{2} \mathrm{O}$ probiótico $(0,03 \%)$ foi adicionado a dieta em substituição à areia lavada. 


\section{RESULTADOS E DISCUSSÃO}

Não houve qualquer diferença significativa para os parâmetros de desempenho e qualidade de ovos (Tabela 2). Esses resultados concordam com NAHASHON $\boldsymbol{e}$ t al. (1994b), que não encontraram diferenças significativas no consumo de ração, qualidade interna e gravidade específica dos ovos com a utilização de probiótico a base de Lactobacillus. A ave em início da postura talvez responda melhor à suplementação de probiótico (PEDROSO et al., 1999). ABDULRAHIM et al. (1996) avaliando probióticos a base de Lactobacillus acidophilus não encontraram diferenças para os parâmetros peso de ovos e espessura da casca, e atribuíram o fato à idade das aves. Também pesquisando os efeitos de probiótico a base de Lactobacillus acidophilus, HADDADIN et al. (1996) observaram que aves com 40 semanas de idade apresentam reduções na concentração de colesterol no plasma e sangue; já com o avanço da sua idade, após oito semanas de administração contínua do microrganismo, os ovos e o plasma das mesmas aves não apresentaram mais a redução do elemento.

Outros autores atribuem a ineficiência no uso de probióticos às boas condições sanitárias que o lote gozava por ocasião do experimento. Conduzindo experimentos com frangos de corte, HENRIQUE (1998), ZUANON et al. (1998) e LODDI (1999) ressaltaram que a falta de desafios proporcionadas por um adequado vazio sanitário e excelentes condições de manejo impossibilitaram a obtenção de resultados favoráveis à utilização de probióticos comerciais.

\section{CONCLUSÕES}

A utilização do Bacillus subtilis como agente probiótico, quando utilizado a partir da recria, da postura ou durante as duas fases, não possibilita melhoras no desempenho e qualidade de ovos de poedeiras de 50 a 66 semanas de idade.

\section{REFERÊNCIAS BIBLIOGRÁFICAS}

ABDULRAHIM, S.M., HADDADIN, M.S.Y., HASHLAMOUN, E.A.R., et al. The influence of Lactobacillus acidophilus and bacitracina on layer performance of chickens and cholesterol content of plasma and egg yolk. British Poultry Science, Edinburgh, v.37, n.2, p.341-346, 1996.

DAMRON, B.L., WILSON, H.R., VOETLE, R.A., et al. A mixed Lactobacillus culture in the diet of broad breasted large white turkey hens. Poultry Science, Champaign, v.60, n.6, p.1350-1351, 1981 .

FÜLLER, R., COLE, C.B. The scientific basis of the probiotic concept. In: STARK, B.A., WILKINSON, J.M. Probiotic: theory and applications. Marlows : Chalcombe, 1988. Cap.1, p.1-4.

GHAZALAH, A.A., EZZAT, I.E., ABDALLA, A.E. Interrelationships of gamma radiation, Lactobacillus and zinc bacitracin in the diet of laying hens. Journal of Agriculture Science of Mansoura University, Mansoura, v.13, n.7, p.1580-1588, 1988 .

GIAMPAULI, J., MORAES, V.M.B., ARIKI, J., et al. Efeito de probiótico sobre o desempenho e qualidade dos ovos de poedeiras após a muda forçada. Revista Brasileira de Ciência Avícola, Campinas, v.1, suplemento 1, p.51, 1999.

GOODLING, A.C., CERNIGLIA, G.J., HERBERT, J.A. Production performance of white leghorn layers fed Lactobacillus fermentation products. Poultry Science, Champaign, v.66, n.3, p.480-486, 1987.

HADDADIN, M.S.Y., ABDULRAHIM, S.M., HASHLAMOUN, E.A.R., et al. The effects of Lactobacillus acidophilus on the production and chemical composition of hen's eggs. Poultry Science, Champaign, v.75, n.4, p.491-494, 1996.

HENRIQUE, A.P.F. Efeito de antibiótico, probiótico e ácidos orgânicos e suas combinações sobre o desempenho e rendimento de carcaça de frangos de corte. Pirassununga, 1998. 88p. Dissertação (Mestrado em Zootecnia) - Curso de Pós-graduação em Zootecnia, Universidade de São Paulo, 1998.

LODDI, M.M. Aspectos Produtivos e qualitativos do uso de probióticos para frangos de corte. Botucatu, 1999. 60p. Dissertação (Mestrado em Zootecnia) - Curso de Pósgraduação em Zootecnia, Universidade Estadual Paulista, 1999.

MILES, R.D., WILSON, H.R., INGRAM, D.R. Productive performance of Bobwhite quail breeders fed a diet containig a Lactobacillus culture. Poultry Science, 
Champaign, v.60, n.7, p.1581-1582, 1981.

MOHAN, B., KADIRVEL, R., BHASKARAN, M., et al. Effect of probiotic suplementation on serum/yolk cholesterol and on egg shell thickness in layers. British Poultry Science, Edinburgh, v.39, n.5, p.799-803, 1995.

NAHASHON, S.N., NAKAUE, H.S., MIROSH, L.W. Effects of direct-fed microbials on nutrient retention and production parametrs of laying pullets. Poultry Science, Champaign, v.71, suplemento 1, p.111, 1992 .

NAHASHON, S.N., NAKAUE, H.S., MIROSH, L.W Production variables and nutrient retention in Single Comb White Leghorn laying pullets fed diets supplemented with direct-fed microbials. Poultry Science, Champaign, v.73, n.12, p.1699-1711, 1994a.

NAHASHON, S.N., NAKAUE, H.S., MIROSH, L.W. Phytase activity, phosphorus and calcium retention, and performance of Single Comb White Leghorn layers fed diets containing two levels of available phosphorus and suplemented with direct-fed microbials. Poultry Science, Champaign, v.73, n. 10, p.1552-1562, 1994 b.
NRC - NATIONAL RESEARCH COUNCIL. Nutrient requirements of poultry. Washington : University, 1994. 155p.

PEDROSO, A.A., MORAES, V.M.B., ARIKI, J. Efeito de níveis de proteína e probiótico (Bacillus subtilis) em rações de frangas e poedeiras comerciais. Revista Brasileira de Ciência Avícola, Campinas, v.1, n.1, p.49-54, 1999.

PHEKOS, G.L., CHAVEZ, E.R., LAGUE, P.C. Dietary flax seed and probiotic supplementation to produce high $\omega$-3 fatty acid and low cholesterol eggs. Poultry Science, Champaign, v.77, suplemento 1, p.42, 1998

SAS. SAS User's guide. Statistics. Cary, North Carolina : SAS Institute, 1998. 956p.

TORTUELO, F., FERNÁNDEZ, E. Effects of inclusion of microbial cultures in barley-based diets fed to laying hens. Animal Feed Science and Technology, Amsterdam, v.53, n.3, p.255-265, 1995.

ZUANON, J.A.S., FONSECA, J.B., ROSTAGNO, H.S., et al. Efeito de promotores de crescimento sobre o desempenho de frangos de corte. Revista Brasileira de Zootecnia, Viçosa, v.27, n.5, p.999-1005, 1998.

Ciência Rural, v. 31, n. 4, 2001. 